\title{
Panax notoginseng saponins alleviates advanced glycation end product-induced apoptosis by upregulating SIRT1 and antioxidant expression levels in HUVECs
}

\author{
YANG BO*, ZHANG JIAN*, SUN ZHI-JUN*, WU QUING*, ZHAO HUA, LI CHUAN-WEI and CAO YU-KANG \\ Department of Cardiology, Chinese PLA General Hospital, Beijing 100853, P.R. China
}

Received March 12, 2016; Accepted April 18, 2019

DOI: $10.3892 /$ etm.2020.9229

\begin{abstract}
The present study examined whether Panax notoginseng saponins (PNS) alleviated advanced glycation end product (AGE)-induced apoptosis in human umbilical vein endothelial cells (HUVECs). HUVECs were incubated with $300 \mu \mathrm{g} / \mathrm{ml}$ AGEs alone or AGEs and PNS $(0.05,0.5$ or $1 \mathrm{mg} / \mathrm{ml})$ for $48 \mathrm{~h}$. The results of the present study demonstrated that PNS effectively promoted cell viability, inhibited apoptosis and suppressed the activity of caspase-3 in AGE-induced HUVECs. The activities of monocyte chemoattractant protein-1 and malondialdehyde were reduced, and superoxide dismutase activity was increased following treatment with PNS. Furthermore, PNS significantly increased the expression of silent information regulator 1 (SIRT1) and transforming growth factor (TGF)- $\beta 1$ proteins, and suppressed the expression of inducible nitric oxide synthase and cyclooxyggenase-2 proteins in AGE-induced HUVECs. Therefore, the present study demonstrated that PNS reduced AGE-induced apoptosis by upregulating SIRT1 and antioxidants in HUVECs. The present findings suggest that the PNS may as an important pharmacological agent for AGE-induced cardiovascular injury.
\end{abstract}

\section{Introduction}

Multiple large-scale clinical studies have indicated that, in the early stages of diabetes, strict regulation of blood glucose levels may reduce the occurrence of diabetic vasculopathy complications, including microangiopathy and macroangiopathy (1). If blood glucose levels of patients with diabetes are not strictly regulated in the long-term, even in cases where levels are controlled in the future, chronic blood vessel complications

Correspondence to: Dr Yang Bo, Department of Cardiology, Chinese PLA General Hospital, 28 Fu-Xing Road, Beijing 100853, P.R. China

E-mail: buyiba432@yeah.net

*Contributed equally

Key words: Panax notoginseng saponins, HUVECs, silent information regulator 1 , antioxidant associated with diabetes may develop (2). This phenomenon is termed as metabolic memory or hyperglycemic memory. Various studies have indicated that if long-term blood glucose levels of patients with diabetes are not efficiently regulated, advanced glycation end products (AGEs) are generated through a series of non-enzyme glycations and lipid oxidations $(2,3)$. This phenomenon may be the primary reason for generating metabolic memory. Previous results have indicated that AGEs are highly correlated with severe degrees of diabetic macroangiopathy and microangiopathy, but have no correlation with other glycated proteins (4). Furthermore, exogenous synthetic AGEs have been demonstrated to damage normal vascular endothelial cells and result in various lesions (5).

Silent information regulator 1 (SIRT1) is a conservative gene in mammalian cells that is located in endothelial cells and belongs to the histone acetylation enzyme family (6). A number of studies have suggested that endonuclear SIRT1 has an important role in maintaining genome stability, regulating cell energy metabolism, lengthening cell survival and delaying cell aging (7). Previous results have revealed that SIRT1 may relieve and decrease various cell functions, including oxidative stress, inflammation and apoptosis, by regulating endothelial cells, endothelial nitric oxide synthase, p53, Foxo family components and endothelial cell regulation by regulating angiotensin receptor II acetylation (8). During the inflammatory response, SIRT1 downregulates nuclear factor (NF)- $\kappa \mathrm{B}$ subunit Rel/65 and B-cell lymphoma associated $\mathrm{X}$ protein $(\mathrm{Bax})$ activity and reduces the generation of inflammatory factors and inhibits suppressor cells (9). Furthermore, it has been indicated that SIRT1 may have a role in inhibiting and promoting cell protection in cardiovascular disease, diabetes mellitus, tumor formation, aging and inflammation $(9,10)$. SIRT1 in sepsis are a few; however, SIRT1 is an important inflammatory and anti-apoptotic factor.

Oxidative stress was first proposed by Seis in 1985 (11). Oxidative stress refers to the overproduction of oxides and limited anti-oxide generation that results in unbalanced pro-oxidation and anti-oxidation, which promotes tissue damage and affects various mechanisms (12). Reactive oxygen species (ROS) are a primary source of oxidative stress and are associated with peroxidation, as well as superoxide anion and free radical generation (13). Additionally, ROS are continuously generated during the metabolic activities of cells (13). Under normal conditions, low concentrations of ROS regulate 
the function of vascular cells and are necessary for the maintenance of normal blood vessel functions (14). However, in cases where ROS are overproduced or not eliminated rapidly, cellular damage of human tissues may occur, including the reduction of nitric oxide activity, lipid oxidation and protein nitration (14). Multiple enzymes are involved in the generation of ROS in vascular endothelial cells, including reduced nicotinamide adenine dinucleotide phosphate (NAPDH), xanthine oxidase, endothelial nitric oxide synthase, cyclooxyggenase-2 (COX-2) and lipoxygenase (15).

The primary component of Panax notoginseng saponins (PNS) injections (Sanqi Panax Notoginseng) are Panax notoginseng saponins (16). PNS are effective pharmacological components of pseudo-ginseng (16). PNS are widely applied in the clinic and are primarily used to carotid artery disease, hemiplegia, sequelae of cerebrovascular disease and chest congestion and pains (16). A previous study has shown that PNS have anti-cerebral ischemic properties, improve blood rheological parameters and microcirculation, reduce the fat composition in the blood and alleviate free radical-induced cell injury (16). Furthermore, PNS are typically used for curing ischemic cerebrovascular diseases and protecting ischemic damage of nerve cells (16). In the present study, it was investigated whether PNS alleviated AGE-induced apoptosis of HUVECs.

\section{Materials and methods}

Reagents, cell culture and treatment. Kaighn's modification of Ham's F-12 medium (F-12 K medium), penicillin and streptomycin were purchased from Invitrogen; Thermo Fisher Scientific, Inc. (Waltham, MA, USA). Fetal calf serum (FCS) was purchased from Gibco; Thermo Fisher Scientific, Inc. Trypsin was obtained from Ameresco, Inc. (Framingham, MA, USA). Human umbilical vein endothelial cells (HUVECs) were purchased from Shanghai Cell Bank of Chinese Academy of Sciences and maintained in F-12 K medium supplemented with $10 \% \mathrm{FBS}, 100 \mathrm{U} / 1$ penicillin and $10 \mathrm{mg} / 1$ streptomycin at $37^{\circ} \mathrm{C}$ in an atmosphere containing $5 \% \mathrm{CO}_{2}$. PNS (95\%) was purchased from Yunnan Botanical Pharmaceutical Co., Ltd. Advanced glycation end product (AGE-BSA) was prepared using D-glucose (Sigma-Aldrich; Merck KGaA) and bovine serum albumin (Beyotime Institute of Biotechnology)

Cell viability. To determine the cell viability, HUVEC cells, at $\sim 85 \%$ confluency, were incubated with F-12 K medium containing $2 \% \mathrm{FBS}$ and $300 \mu \mathrm{g} / \mathrm{ml} \mathrm{AGE}$ alone or AGE and PNS $(0.05,0.5$ or $1 \mathrm{mg} / \mathrm{ml})$ for $48 \mathrm{~h}$ in a humidified atmosphere containing $5 \% \mathrm{CO}_{2}$. The control group consisted of HUVEC cells incubated with F-12 K medium containing $2 \%$ FBS. Following a $4 \mathrm{~h}$ incubation period at $37^{\circ} \mathrm{C}$ with $50 \mu 1$ 3-(4,5-dimethyl-thiazol-2-yl)-2,5-diphenyltetrazolium bromide (MTT; $5 \mathrm{mg} / \mathrm{ml}$; Invitrogen; Thermo Fisher Scientific, Inc.), the medium was discarded and $150 \mu \mathrm{l}$ of dimethyl sulfoxide (Sigma-Aldrich; Merck KGaA, Darmstadt, Germany) was added. Cell viability was measured using a microplate reader (Model 550; Bio-Rad Laboratories, Inc., Hercules, CA, USA).

Apoptosis rate assay. HUVEC cells, at $~ 85 \%$ confluency, were incubated with F-12 K medium containing 2\% FBS and
$300 \mu \mathrm{g} / \mathrm{ml}$ AGE or PNS $(0.05,0.5$ or $1 \mathrm{mg} / \mathrm{ml})$ for $48 \mathrm{~h}$. Cells in the control group were treated with PBS. Cells were washed twice with $4^{\circ} \mathrm{C}$ phosphate-buffered saline and resuspended in $100 \mu \mathrm{l}$ binding buffer (Invitrogen; Thermo Fisher Scientific, Inc.). Cell was fixed with $4 \%$ paraformaldehyde for $15 \mathrm{~min}$ at room temperature. Subsequently, cells were stained with $5 \mu \mathrm{l}$ Annexin V-fluorescein isothiocyanate (FITC) and $5 \mu \mathrm{l}$ propidium iodide (PI) for $15 \mathrm{~min}$ at room temperature in the dark. The apoptotic rate was quantified using the Coulter Epics XL flow cytometer (Beckman Coulter, Inc., Brea, CA, USA).

ELISA. HUVEC cells $\left(1 \times 10^{6}\right.$ cells $/ \mathrm{ml}, 200 \mu \mathrm{l} /$ well in 96 well plates) at a confluency of $\sim 85 \%$ were incubated with F-12 K medium supplemented with $2 \% \mathrm{FBS}$ and $300 \mu \mathrm{g} / \mathrm{ml}$ AGE alone or AGE and PNS $(0.05,0.5$ or $1 \mathrm{mg} / \mathrm{ml})$ for $48 \mathrm{~h}$ in a humidified atmosphere containing $5 \% \mathrm{CO}_{2}$. The control group consisted of HUVEC cells incubated with F-12 K medium containing $2 \% \mathrm{FBS}$ at $37^{\circ} \mathrm{C}$. Cells were lysed in ice-cold cell lysis buffer (Cell Signaling Technology, Inc., Danvers, MA, USA) and protease cocktails (1:100; Gibco; Thermo Fisher Scientific, Inc.). The supernatant was collected to measure the contents of caspase-3 (cat. no. G015-1-3; Nanjing Jiancheng Biology Engineering Institute, Nanjing, China), monocyte chemoattractant protein-1 (MCP-1; cat. no. H115; Nanjing Jiancheng Biology Engineering Institute), malondialdehyde (MDA; cat. no. A003-1-2; Nanjing Jiancheng Biology Engineering Institute) and sodium dismutase superoxide dismutase (SOD; cat. no. A001-3-2; Nanjing Jiancheng Biology Engineering Institute) using an ELISA reader (Start Fax 2100; Awareness Technology Inc., Fisher Bioblock Scientific, Tournai, Belgium).

Western blotting. HUVEC cells were incubated with F-12 K medium containing $2 \% \mathrm{FBS}$ and $300 \mu \mathrm{g} / \mathrm{ml}$ AGE alone or AGE and PNS (control, 0.05, 0.5 or $1 \mathrm{mg} / \mathrm{ml}$ ) for $48 \mathrm{~h}$ in a humidified atmosphere containing $5 \% \mathrm{CO}_{2}$. Control group was HUVEC cells incubated with F-12 K medium containing $2 \%$ FBS at $37^{\circ} \mathrm{C}$. Cell was lysed in ice-cold cell lysis buffer (Cell Signaling Technology, Inc.) and protease cocktails. Protein concentration was determined using a BCA protein assay kit (Thermo Fisher Scientific, Inc.) according to the manufacturer's instructions. Equal quantities of protein $(50 \mu \mathrm{g})$ were loaded and separated using SDS-PAGE (10\% gels) and transferred to polyvinylidene difluoride (PVDF) membranes (GE Healthcare Life Sciences, Chalfont, UK). Following this, membranes were blocked with $5 \%$ milk solution (Yili Group Co., Ltd., Neimenggu, China) in $0.1 \%$ Tris-buffered saline tween (TBS-T) for $2 \mathrm{~h}$ at room temperature. Target protein bands in the PVDF membranes were probed with anti-silent information regulator 1 (SIRT1; cat. no. sc-74465, 1:1,000, Santa Cruz Biotechnology, Inc., Dallas, TX, USA), anti-transforming growth factor (TGF)- $\beta 1$ (cat. no. 3709; 1:1,000; Cell Signaling Technology Inc.), anti-inducible nitric oxide synthase (iNOS, cat. no. 13120, 1:1,000, Cell Signaling Technology, Inc.), anti-cyclooxygenase 2 and anti-GAPDH (cat. no. 5174, 1:1,000, Cell Signaling Technology, Inc.) at $4^{\circ} \mathrm{C}$ overnight. Following washing with TBS-T for 5 min for a total of three times, PVDF membranes were incubated with Anti-rabbit IgG, HRP-linked Antibody (cat. no. 7074; 1:5,000; Cell Signaling Technology Inc.) for $1 \mathrm{~h}$ at $37^{\circ} \mathrm{C}$. Bands were detected using enhanced chemiluminescence reagents (SuperSignal West 
Femto, Pierce; Thermo Fisher Scientific, Inc.). Images were captured using a FluorChem FC2 Imaging System (Alpha Innotech Corp., San Leandro, CA, USA).

Statistical analysis. Data are indicated as mean \pm standard error of the mean using SPSS software (version 11.0; SPSS, Inc., Chicago, IL, USA). Data were analyzed using one-way analysis of variance analysis and Tukey's post hoc test for three groups or data were analyzed using Student's t-test for two groups. $\mathrm{P}<0.05$ was considered to indicate a statistically significant difference.

\section{Results}

PNS promotes cell viability of AGE-induced HUVECs. AGE-induced HUVECs were established to study the effect of PNS on cell viability of AGE-induced HUVECs. Cell viability of AGE-induced HUVECs was determined using the MTT assay. As indicated in Fig. 1, the cell viability of AGE-induced HUVECs was significantly reduced compared with that of the control $(\mathrm{P}<0.01)$. However, AGE-treated cells with 0.5 or $1 \mathrm{mg} / \mathrm{ml}$ PNS exhibited significantly increased cell viability of AGE-induced HUVECs compared with that of the AGE-induced HUVECs model (P<0.01; Fig. 1).

PNS inhibits the apoptotic rate of AGE-induced HUVECs. Annexin V-FITC/PI was performed to examine the effect of PNS on the apoptotic rate in AGE-induced HUVECs. A significant increase in the apoptotic rate was exhibited in AGE-induced HUVECs compared with the control group ( $\mathrm{P}<0.01$; Fig. 2). Compared with the AGE-induced HUVECs model group, the apoptotic rate of AGE-induced HUVECs was significantly decreased by 0.5 or $1 \mathrm{mg} / \mathrm{ml} \mathrm{PNS} \mathrm{treatment}$ ( $\mathrm{P}<0.01$; Fig. 2).

PNS suppresses caspase-3 activity of AGE-induced HUVECs. The effect of PNS on caspase-3 activity was evaluated in AGE-induced HUVECs. AGE significantly induced caspase-3 activity in HUVECs compared with that of the control group

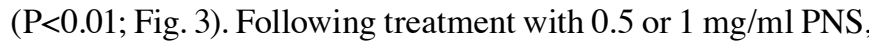
caspase-3 activity in AGE-induced HUVECs was significantly reduced compared with the AGE-induced HUVECs model ( $\mathrm{P}<0.01 ;$ Fig. 3).

PNS suppresses MCP-1 and MDA activities and increases SOD activity in AGE-induced HUVECs. The present study explored the protective effect of PNS on AGE-induced HUVECs, specifically exploring the effect of PNS on MCP-1, MDA and SOD. As indicated in Fig. 4, AGEs significantly increased the levels of MCP-1 and MDA and decreased the levels of SOD in HUVECs compared with control group (all $\mathrm{P}<0.01)$. However, treatment with 0.5 or $1 \mathrm{mg} / \mathrm{ml}$ PNS significantly reduced the MCP-1 and MDA levels and increased the levels of SOD in AGE-induced HUVECs compared with the AGE-induced HUVECs model (P<0.01; Fig. 4).

PNS promotes the protein expression levels of SIRT1 in AGE-induced HUVECs. To investigate the mechanism by which AGE-induced HUVECs are regulated when treated with PNS, the protein expression levels of SIRT1 protein were

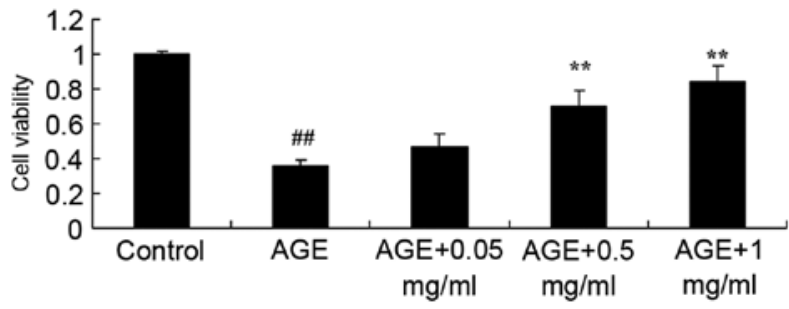

Figure 1. PNS promotes the cell viability of AGE-induced HUVECs. ${ }^{\# \#} \mathrm{P}<0.01$ vs. control group; ${ }^{* *} \mathrm{P}<0.01$ vs. AGE group. Control, cells without treatment group; AGE, AGE-induced HUVECs group; $\mathrm{AGE}+0.05 \mathrm{mg} / \mathrm{ml}$, AGE-induced HUVECs + $0.05 \mathrm{mg} / \mathrm{ml}$ PNS group; $\mathrm{AGE}+0.5 \mathrm{mg} / \mathrm{ml}$, AGE-induced HUVECs $+0.5 \mathrm{mg} / \mathrm{ml}$ PNS group; $\mathrm{AGE}+1 \mathrm{mg} / \mathrm{ml}$, AGE-induced HUVECs $+1 \mathrm{mg} / \mathrm{ml}$ PNS group. HUVECs, human umbilical vein endothelial cells; PNS, Panax notoginseng saponins; AGE, advanced glycation end products.

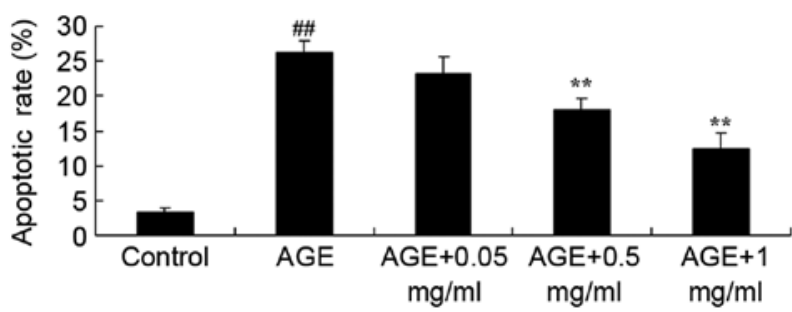

Figure 2. PNS inhibits apoptosis of AGE-induced HUVECs. ${ }^{\# \#} \mathrm{P}<0.01$ vs. Control group; ${ }^{* *} \mathrm{P}<0.01$ vs. AGE group. Control, HUVECs without AGE and PNS (Control group); AGE, AGE-induced HUVECs group; AGE + $0.05 \mathrm{mg} / \mathrm{ml}$, AGE-induced HUVECs $+0.05 \mathrm{mg} / \mathrm{ml}$ PNS group; AGE + $0.5 \mathrm{mg} / \mathrm{ml}$, AGE-induced HUVECs $+0.5 \mathrm{mg} / \mathrm{ml}$ PNS group; AGE $+1 \mathrm{mg} / \mathrm{ml}$, AGE-induced HUVECs $+1 \mathrm{mg} / \mathrm{ml}$ PNS group. HUVECs, human umbilical vein endothelial cells; PNS, Panax notoginseng saponins; AGE, advanced glycation end products.

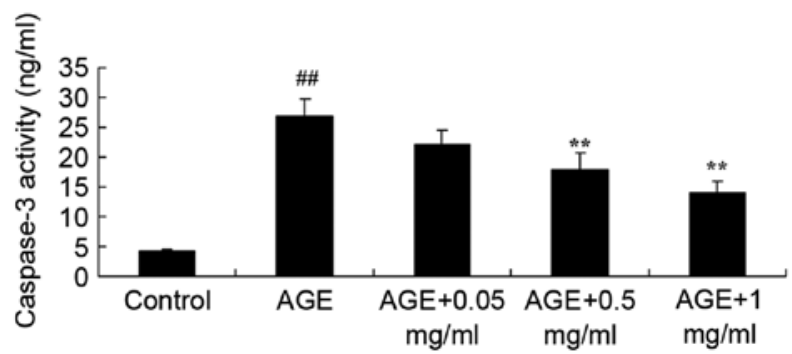

Figure 3. PNS suppresses caspase-3 activity of AGE-induced HUVECs. ${ }^{\# \#} \mathrm{P}<0.01$ vs. Control group; ${ }^{* *} \mathrm{P}<0.01$ vs. AGE group. Control, HUVECs without AGE and PNS (Control group); AGE, AGE-induced HUVECs group; AGE $+0.05 \mathrm{mg} / \mathrm{ml}$, AGE-induced HUVECs $+0.05 \mathrm{mg} / \mathrm{ml}$ PNS group; AGE $+0.5 \mathrm{mg} / \mathrm{ml}$, AGE-induced HUVECs $+0.5 \mathrm{mg} / \mathrm{ml}$ PNS group; AGE $+1 \mathrm{mg} / \mathrm{ml}$, AGE-induced HUVECs $+1 \mathrm{mg} / \mathrm{ml}$ PNS group. HUVECs, human umbilical vein endothelial cells; PNS, Panax notoginseng saponins; AGE, advanced glycation end products.

investigated in HUVECs. AGEs significantly reduced the protein expression levels of SIRT1 in AGE-induced HUVECs compared with the control group $(\mathrm{P}<0.01$ : Fig. 5). However, 0.5 or $1 \mathrm{mg} / \mathrm{ml}$ PNS treatment significantly increased the protein expression levels of SIRT1 in AGE-induced HUVECs compared with the AGE-induced HUVECs model $(\mathrm{P}<0.01 ;$ Fig. 5).

PNS promotes the protein expression levels of TGF- $\beta 1$ in $A G E$-induced HUVECs. To investigate whether TGF- $\beta 1$ regulates AGE-induced HUVECs by PNS, the present 


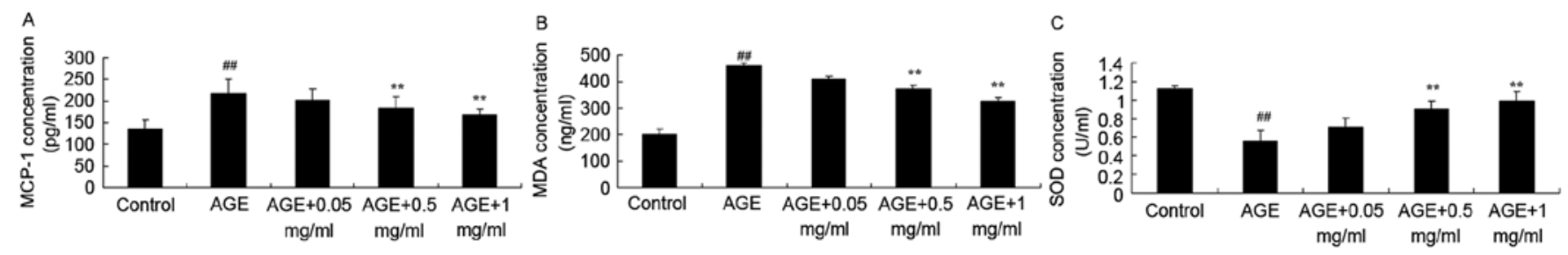

Figure 4. PNS suppresses MCP-1 and MDA activity and increases SOD activity of AGE-induced HUVECs. PNS suppressed (A) MCP-1 and (B) MDA activity and (C) increased SOD activity of AGE-induced HUVECs. ${ }^{\# \#} \mathrm{P}<0.01$ vs. Control group; ${ }^{* *} \mathrm{P}<0.01$ vs. AGE group. Control, HUVECs without AGE and PNS (Control group); AGE, AGE-induced HUVECs group; AGE + $0.05 \mathrm{mg} / \mathrm{ml}$, AGE-induced HUVECs + $0.05 \mathrm{mg} / \mathrm{ml}$ PNS group; AGE + 0.5 mg/ml, AGE-induced HUVECs $+0.5 \mathrm{mg} / \mathrm{ml}$ PNS group; AGE $+1 \mathrm{mg} / \mathrm{ml}$, AGE-induced HUVECs $+1 \mathrm{mg} / \mathrm{ml}$ PNS group. HUVECs, human umbilical vein endothelial cells; AGE, advanced glycation end products; PNS, Panax notoginseng saponins; MCP-1, monocyte chemoattractant protein-1; MDA, malondialdehyde; SOD, superoxide dismutase.

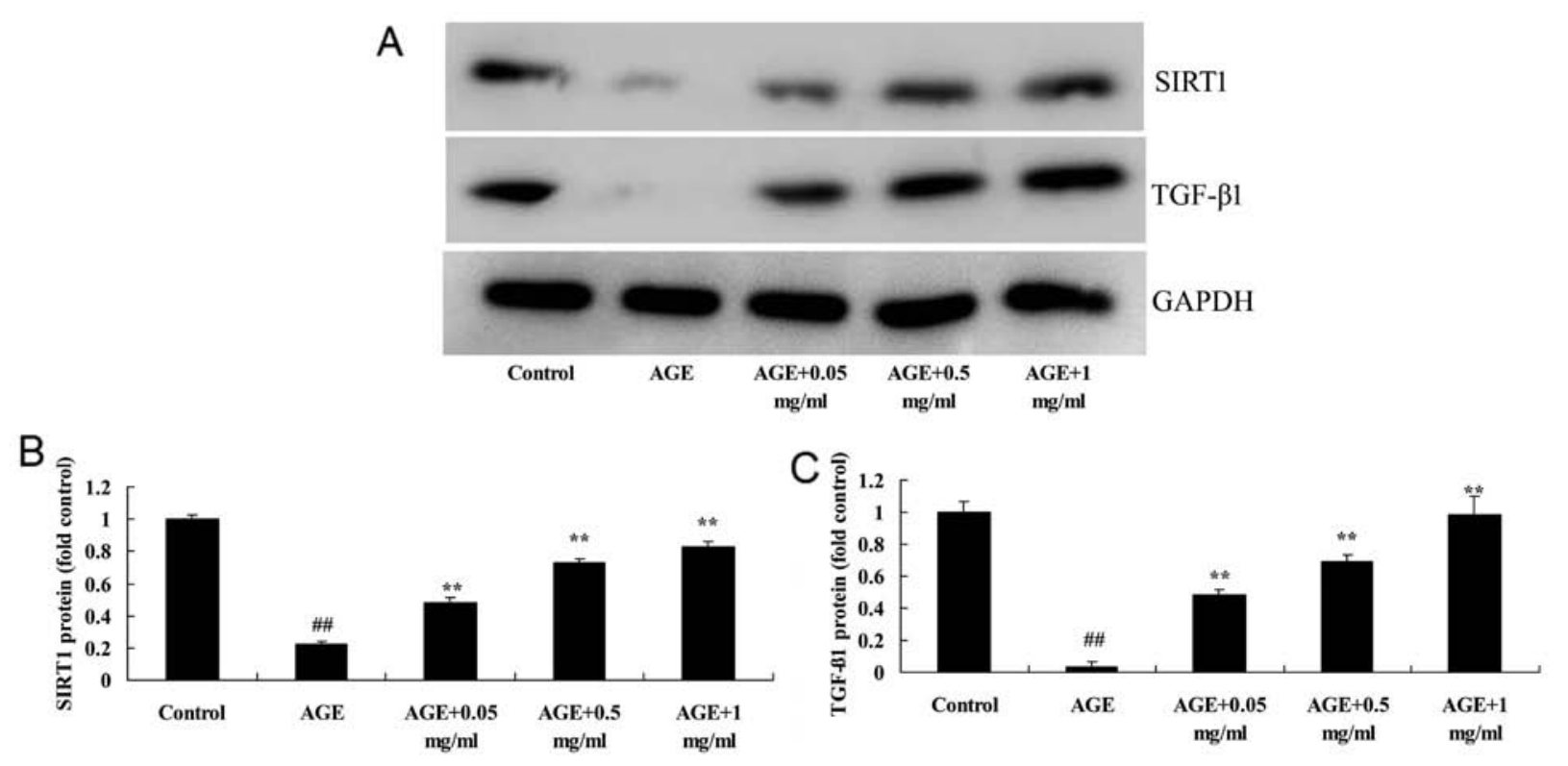

Figure 5. PNS activates SIRT1 and TGF- $\beta 1$ protein expression of AGE-induced HUVECs. (A) Western blotting and (B and C) statistical analysis was performed and indicated that PNS suppressed SIRT1 and TGF- $\beta 1$ protein expression levels of AGE-induced HUVECs. ${ }^{\# \#} \mathrm{P}<0.01$ vs. Control group; ${ }^{* *} \mathrm{P}<0.01$ vs. AGE group. Control, HUVECs without AGE and PNS (Control group); AGE, AGE-induced HUVECs group; AGE + 0.05 mg/ml, AGE-induced HUVECs + $0.05 \mathrm{mg} / \mathrm{ml}$ PNS group; AGE $+0.5 \mathrm{mg} / \mathrm{ml}$, AGE-induced HUVECs $+0.5 \mathrm{mg} / \mathrm{ml}$ PNS group; AGE $+1 \mathrm{mg} / \mathrm{ml}$, AGE-induced HUVECs $+1 \mathrm{mg} / \mathrm{ml}$ PNS group HUVECs, human umbilical vein endothelial cells; AGE, advanced glycation end products; PNS, Panax notoginseng saponins; SIRT1, silent information regulator 1 ; TGF- $\beta 1$, transforming growth factor- $\beta 1$.

study analyzed the protein expression levels of TGF- $\beta 1$ in AGE-induced HUVECs. As revealed in Fig. 6, the protein expression levels of TGF- $\beta 1$ were significantly reduced compared with the control group $(\mathrm{P}<0.01)$. TGF- $\beta 1$ protein expression levels were significantly increased by 0.5 or $1 \mathrm{mg} / \mathrm{ml}$ PNS treatment compared with the AGE-induced HUVECs model ( $\mathrm{P}<0.01$; Fig. 5).

PNS suppresses the protein expression levels of iNOS in AGE-induced HUVECs. The present study observed that the iNOS protein expression levels of AGE-induced HUVECs were significantly increased compared with the control group ( $\mathrm{P}<0.01$; Fig. 6). However, 0.5 or $1 \mathrm{mg} / \mathrm{ml}$ PNS treatment significantly reduced AGE-induced iNOS protein expression levels in HUVECs compared with the AGE-induced HUVECs model $(\mathrm{P}<0.01$; Fig. 6$)$.

PNS suppresses the protein expression levels of $\mathrm{COX}-2$ in AGE-induced HUVECs. To further explore the effect of PNS in AGE-induced HUVECs, the protein expression levels of COX-2 in AGE-induced HUVECs were examined. As indicated in Fig. 6, COX-2 protein expression levels in AGE-induced HUVECs were significantly increased compared with the control group $(\mathrm{P}<0.01)$. Treatment with 0.5 and $1 \mathrm{mg} / \mathrm{ml}$ PNS significantly inhibited AGE-induced COX-2 protein expression levels in HUVECs compared with the AGE-induced HUVECs model ( $\mathrm{P}<0.01$; Fig. 6).

\section{Discussion}

It is largely acknowledged that oxidative stress is a dangerous factor of coronary heart disease (17). Changes in vascular endothelial function and structure in diabetes is one of predominant causes of disability and mortality (18). An animal study indicated that, during the progression of disease in rats, AGEs in tissues are increased and impact the normal functions of tissues (18). For cardiovascular protection, candesartan is typically administered in clinic settings, which has been shown to downregulate the expression of AGE receptors in diabetic rats and reduce the generation of AGEs (5). A previous study has demonstrated that 


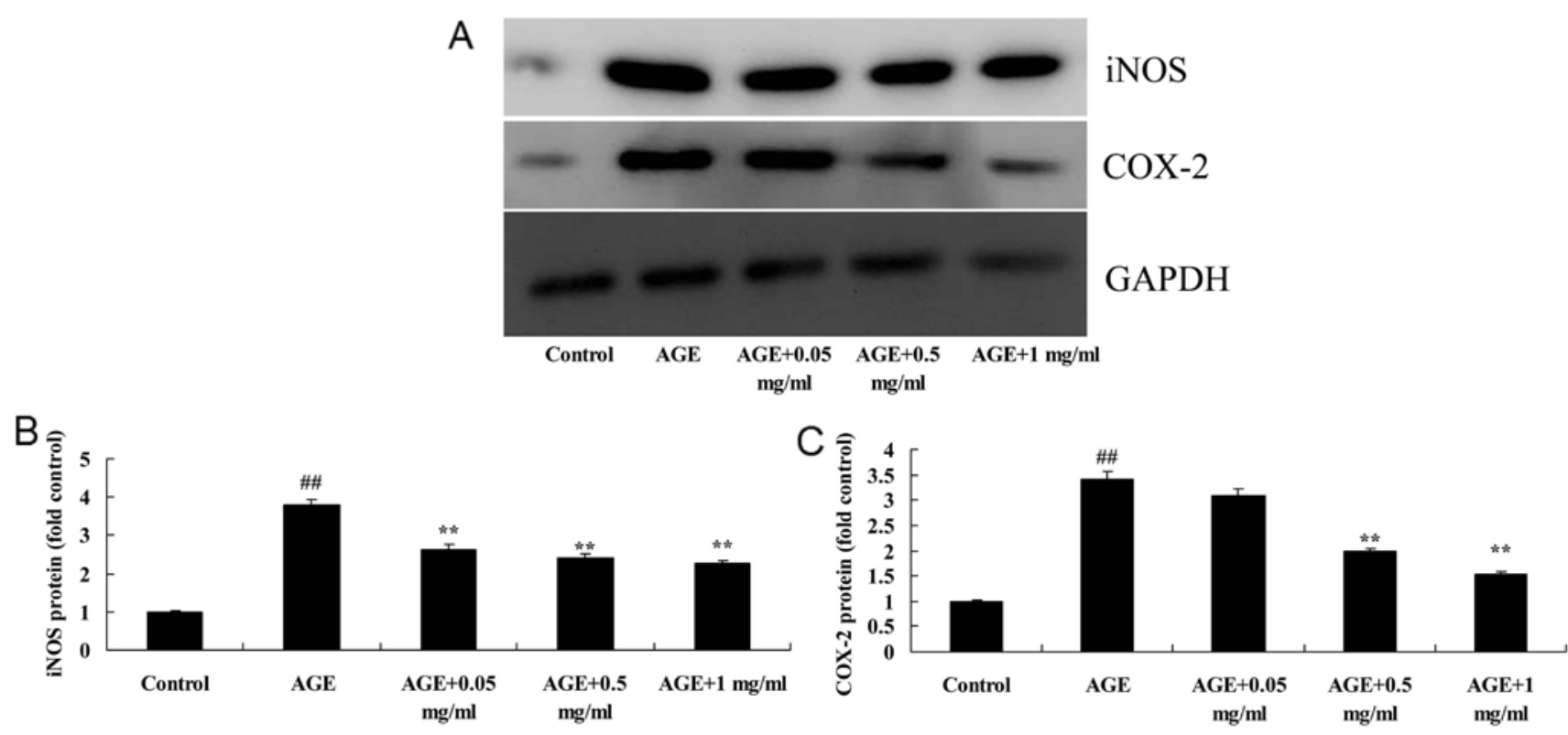

Figure 6. PNS suppresses iNOS and COX-2 protein expression levels in AGE-induced HUVECs. (A) Western blotting and (B and C) statistical analysis indicated that PNS suppressed iNOS and COX-2 protein expression levels in AGE-induced HUVECs. ${ }^{\# \#} \mathrm{P}<0.01$ vs. Control group; ${ }^{* *} \mathrm{P}<0.01$ vs. AGE group. Control, HUVECs without AGE and PNS (Control group); AGE, AGE-induced HUVECs group; AGE $+0.05 \mathrm{mg} / \mathrm{ml}$, AGE-induced HUVECs $+0.05 \mathrm{mg} / \mathrm{ml}$ PNS group; AGE + $0.5 \mathrm{mg} / \mathrm{ml}$, AGE-induced HUVECs $+0.5 \mathrm{mg} / \mathrm{ml}$ PNS group; AGE + $1 \mathrm{mg} / \mathrm{ml}$, AGE-induced HUVECs + $1 \mathrm{mg} / \mathrm{ml} \mathrm{PNS} \mathrm{group.} \mathrm{HUVECs,}$ human umbilical vein endothelial cells; AGE, advanced glycation end products; PNS, Panax notoginseng saponins; iNOS, inducible nitric oxide synthase; COX-2, cyclooxyggenase-2.

long-term hyperglycemia reduces mitochondrial functions and generates superfluous superoxide. Tissue proteins and nucleic acids undergo glycation and generate multiple AGEs (19). AGEs can coat mitochondrial proteins, restrain mitochondrial proteins and promote the generation of super-oxygen ions (20). During the progression of hyperglycemia, damage to the cell accumulates (20). It has been demonstrated that even if hyperglycemia is corrected, the damage provoked by AGEs is irreversible (21). SOD levels and suppressed AGE-induced iNOS and COX-2 expression in AGE-induced HUVECs. Peng et al (21) demonstrated that $P$.notoginseng flower saponins (PNFS) significantly downregulated iNOS gene expression in RAW264.7 macrophages. Ding et al (16) demonstrated that PNFS reduced acute ethanol-induced liver injury through reducing ethanol-mediated oxidative stress.

TGF- $\beta 1$ has multiple roles in regulating cardiovascular physiology and disease (22). One important role of TGF- $\beta 1$ is to regulate endothelial cell function in the blood vascular system (23). Unbalanced TGF- $\beta 1$ signaling results in abnormalities in embryo vascular development (24). Furthermore, TGF- $\beta 1$ has an important role in the formation of new blood capillaries (24). Furthermore, a previous study indicated that TGF- $\beta 1$ regulated proliferation, apoptosis, changes of permeability and morphogenesis of endothelial cells (24). It has been demonstrated that, in patients with typical precursors of cardiovascular disease, such as obesity or diabetes, TGF- $\beta 1$ plasma concentration is increased (23). The present findings revealed that PNS treatment significantly induced TGF- $\beta 1$ protein expression in AGE-induced HUVECs. Hu et al (25) revealed that PNS significantly inhibited the expression of TGF- $\beta 1$ in rats with peritoneal fibrosis.

Aging is the response of body to multiple factors within the internal and external environment (26). Conditions such as radiation, anoxia, peroxidation, high glucose or hyperlipidaemia promote aging; however, aging is not determined by a single factor. In the literature, various aging markers have been indicated, such as telomerase, $\beta$-galactosidase and SIRT1 gene (26). SIRT1 has been implicated in gene silencing, resisting stress and prolonging lifespan (27). Furthermore, multiple studies have indicated that the SIRT1 gene has an important role on aging $(26,27)$. Previous results demonstrated that knockout of SIRT1 may promote animal aging (26). Furthermore, a previous study has suggested that SIRT1 is a key factor for resisting outside stimulation, oxidative stress, inflammation and autophagy (7). Reports have demonstrated that SIRT1 may prevent oxidative stress by inducing premature-aging of HUVECs and inhibiting premature senility of oxidative stress, while increased SIRT1 expression plays an important role in the aging phenotype of HUVECs $(28,29)$. Results from the present study demonstrated that PNS treatment significantly increased SIRT1 protein expression in AGE-induced HUVECs and suggested that the SIRT1 pathway has an important role in the sensitization effect of PNS to vasculopathy. Du et al (30) reported that PNS protects the kidneys of rats from diabetes by upregulating SIRT1 and antioxidant effects.

In conclusion, the present study revealed that PNS significantly promoted the cell viability, inhibited the AGE-induced apoptotic rate, inhibited MCP-1 and MDA levels, increased SOD levels and suppressed AGE-induced iNOS and COX-2 protein expression levels in HUVECs, potentially through upregulating SIRT1 and TGF- $\beta 1$. The present study indicated the SIRT1 and TGF- $\beta 1$ are likely involved in PNS-induced protection of AGE-induced cardiovascular injury. 


\section{Acknowledgements}

Not applicable.

\section{Funding}

This work was partly supported by the National Natural Science Foundation of China (grant no. 81570272; Bo Yang), the Beijing Natural Science Foundation (grant no. 7132227; Bo Yang), the Nova Programme from Beijing Municipal Science and Technology Commission (grant no. Z1411 07001814113-XXHZ- 201401; Bo Yang) and Discovery Foundation from The Chinese Medical Doctor Association (grant no. DFCMDA201311; Bo Yang).

\section{Availability of data and materials}

The datasets used and/or analyzed during the current study are available from the corresponding author on reasonable request.

\section{Authors' contributions}

YB designed the experiment. YB, ZJ, SZJ, WQ, ZH, LCW and CYK performed the experiments. YB analyzed the data. YB wrote the manuscript. All authors read and approved the final manuscript.

\section{Ethics approval and consent to participate}

Not applicable.

\section{Patient consent for publication}

Not applicable.

\section{Competing interests}

The authors declare that they have no competing interests.

\section{References}

1. Writing Committee for the Diabetic Retinopathy Clinical Research Network, Gross JG, Glassman AR, Jampol LM, Inusah S, Aiello LP, Antoszyk AN, Baker CW, Berger BB, Bressler NM, et al: Panretinal photocoagulation vs. intravitreous ranibizumab for proliferative diabetic retinopathy: A randomized clinical trial. JAMA 314: 2137-2146, 2015.

2. de Franciscis S, GallelliL, BattagliaL, Molinari V, Montemurro R, Stillitano DM, Buffone G and Serra R: Cilostazol prevents foot ulcers in diabetic patients with peripheral vascular disease. Int Wound J 12: 250-253, 2015.

3. Davis KE, Prasad C, Vijayagopal P, Juma S, Adams-Huet B and Imrhan V: Contribution of dietary advanced glycation end products (AGE) to circulating AGE: Role of dietary fat. Br J Nutr 114: 1797-1806, 2015.

4. Komosinska-Vassev K, Olczyk P, Winsz-Szczotka K, Klimek K and Olczyk K: Plasma biomarkers of oxidative and AGE-mediated damage of proteins and glycosaminoglycans during healthy ageing: A possible association with ECM metabolism. Mech Ageing Dev 133: 538-548, 2012.

5. Calfee CS, Ware LB, Eisner MD, Parsons PE, Thompson BT, Wickersham N and Matthay MA; NHLBI ARDS Network: Plasma receptor for advanced glycation end products and clinical outcomes in acute lung injury. Thorax 63: 1083-1089, 2008.
6. Hipps D, Ausania F, Manas DM, Rose JD and French JJ: Selective interarterial radiation therapy (SIRT) in colorectal liver metastases: How do we monitor response? HPB Surg 2013: 570808, 2013.

7. Mortuza R, Chen S, Feng B, Sen S and Chakrabarti S: High glucose induced alteration of SIRTs in endothelial cells causes rapid aging in a p300 and FOXO regulated pathway. PLoS One 8: e54514, 2013

8. Donato AJ, Morgan RG, Walker AE and Lesniewski LA: Cellular and molecular biology of aging endothelial cells. J Mol Cell Cardiol 89: 122-135, 2015.

9. Roy A, Zhang M, Saad Y and Kolattukudy PE: Antidicer RNAse activity of monocyte chemotactic protein-induced protein-1 is critical for inducing angiogenesis. Am J Physiol Cell Physiol 305: C1021-C1032, 2013

10. Marampon F, Gravina GL, Scarsella L, Festuccia C, Lovat F, Ciccarelli C, Zani BM, Polidoro L, Grassi D, Desideri G, et al: Angiotensin-converting-enzyme inhibition counteracts angiotensin II-mediated endothelial cell dysfunction by modulating the p38/SirT1 axis. J Hypertens 31: 1972-1983, 2013.

11. Madani Z, Malaisse WJ and Ait-Yahia D: A comparison between the impact of two types of dietary protein on brain glucose concentrations and oxidative stress in high fructose-induced metabolic syndrome rats. Biomed Rep 3: 731-735, 2015.

12. Mooradian AD, Onstead-Haas L and Haas MJ: Asymmetrical cross-talk between the endoplasmic reticulum stress and oxidative stress caused by dextrose. Life Sci 144: 37-48, 2016.

13. Bone DB, Antic M, Vilas G and Hammond JR: Oxidative stress modulates nucleobase transport in microvascular endothelial cells. Microvasc Res 95: 68-75, 2014.

14. Nagar H, Jung SB, Kwon SK, Park JB, Shong M, Song HJ, Jeon BH, Irani $\mathrm{K}$ and Kim CS: CRIF1 deficiency induces p66shc-mediated oxidative stress and endothelial activation. PLoS One 9: e98670, 2014.

15. Roy A and Kolattukudy PE: Monocyte chemotactic protein-induced protein (MCPIP) promotes inflammatory angiogenesis via sequential induction of oxidative stress, endoplasmic reticulum stress and autophagy. Cell Signal 24: 2123-2131, 2012.

16. Ding RB, Tian K, Cao YW, Bao JL, Wang M, He C, Hu Y, Su H and Wan JB: Protective effect of panax notoginseng saponins on acute ethanol-induced liver injury is associated with ameliorating hepatic lipid accumulation and reducing ethanol-mediated oxidative stress. J Agric Food Chem 63: 2413-2422, 2015.

17. Lopes-Virella MF, Baker NL, Hunt KJ, Lyons TJ, Jenkins AJ and Virella G; DCCT/EDIC Study Group: High concentrations of AGE-LDL and oxidized LDL in circulating immune complexes are associated with progression of retinopathy in type 1 diabetes. Diabetes Care 35: 1333-1340, 2012.

18. Ng ZX, Chua KH, Iqbal T and Kuppusamy UR: Soluble receptor for advanced glycation end-product (sRAGE)/pentosidine ratio: A potential risk factor determinant for type 2 diabetic retinopathy. Int J Mol Sci 14: 7480-7491, 2013.

19. Stróżecki P, Kurowski R, Flisiński M, Stefańska A, Odrowąz-Sypniewska G and Manitius J: Advanced glycation end products and arterial stiffness in patients with diabetic nephropathy and patients with chronic kidney disease without diabetes. Pol Arch Med Wewn 123: 609-616, 2013.

20. You WH, Wang P, Li MQ, Zhang Y, Peng YL and Zhang FL: Therapeutic effects of modified Danggui Sini Decoction on plasma level of advanced glycation end products in patients with Wagner grade 0 diabetic foot: A randomized controlled trial. Zhong Xi Yi Jie He Xue Bao 7: 622-628, 2009.

21. Peng XX, Zhang SH, Wang XL, Ye TJ, Li H, Yan XF, Wei L, Wu ZP, Hu J, Zou CP, et al: Panax notoginseng flower saponins (PNFS) inhibit LPS-stimulated NO overproduction and iNOS gene overexpression via the suppression of TLR4-mediated MAPK/NF-kappa B signaling pathways in RAW264.7 macrophages. Chin Med 10: 15, 2015.

22. Eiselein L, Nyunt T, Lamé MW, Ng KF, Wilson DW, Rutledge JC and Aung HH: TGRL lipolysis products induce stress protein ATF3 via the TGF- $\beta$ receptor pathway in human aortic endothelial cells. PLoS One 10: e0145523, 2015.

23. Star GP, Giovinazzo M and Langleben D: Effects of bone morphogenic proteins and transforming growth factor-beta on In-vitro production of endothelin-1 by human pulmonary microvascular endothelial cells. Vascul Pharmacol 50: 45-50, 2009.

24. Ferrari G, Terushkin V, Wolff MJ, Zhang X, Valacca C, Poggio P, Pintucci $G$ and Mignatti P: TGF- $\beta 1$ induces endothelial cell apoptosis by shifting VEGF activation of p38(MAPK) from the prosurvival p38 $\beta$ to proapoptotic p38 $\alpha$. Mol Cancer Res 10: 605-614, 2012 
25. Hu W, Zhang Y and Sigdel KR: The effects of Panax notoginseng saponins on the cytokines and peritoneal function in rats with peritoneal fibrosis. Ren Fail 37: 1507-1513, 2015.

26. Gao R, Wang Y, Pan Q, Huang G, Li N, Mou J and Wang D: Fuzhisan, a chinese herbal medicine, suppresses beta-secretase gene transcription via upregulation of SIRT1 expression in N2a-APP695 cells. Int J Clin Exp Med 8: 7231-7240, 2015.

27. Takizawa Y, Kosuge Y, Awaji H, Tamura E, Takai A, Yanai T, Yamamoto R, Kokame K, Miyata T, Nakata R and Inoue H: Up-regulation of endothelial nitric oxide synthase (eNOS), silent mating type information regulation 2 homologue 1 (SIRT1) and autophagy-related genes by repeated treatments with resveratrol in human umbilical vein endothelial cells. Br J Nutr 110 2150-2155, 2013.

28. Ota H, Eto M, Kano MR, Kahyo T, Setou M, Ogawa S, Iijima K, Akishita M and Ouchi Y: Induction of endothelial nitric oxide synthase, SIRT1, and catalase by statins inhibits endothelial senescence through the Akt pathway. Arterioscler Thromb Vasc Biol 30: 2205-2211, 2010.
29. Suo R, Zhao ZZ, Tang ZH, Ren Z, Liu X, Liu LS, Wang Z, Tang CK, Wei DH and Jiang ZS: Hydrogen sulfide prevents $\mathrm{H}_{2} \mathrm{O}_{2}$-induced senescence in human umbilical vein endothelial cells through SIRT1 activation. Mol Med Rep 7: 1865-1870, 2013.

30. Du YG, Wang LP, Qian JW, Zhang KN and Chai KF: Panax notoginseng saponins protect kidney from diabetes by up-regulating silent information regulator 1 and activating antioxidant proteins in rats. Chin J Integr Med 22: 910-917, 2016.

This work is licensed under a Creative Commons Attribution-NonCommercial-NoDerivatives 4.0 International (CC BY-NC-ND 4.0) License. 